\title{
TIME TO MODIFY OPERATING SOFTWARE (OS), DATABASES (DB) AND TCP/IP PROTOCOLS FOR DATA TRASH ELIMINATION, BASED ON USER DEFINED SHELF LIFE OF DATA
}

\author{
Sarvesh Kumar Tripathi \\ Mother Dairy Fruits \& Vegetable Pvt. Ltd, Delhi, India \\ Dr Avjeet Kaur \\ KR Mangalam University, Gurugram, India \\ Dr RK Pandey \\ KR Mangalam University, Gurugram, India \\ Dr Meghna Chhabra \\ Manav Rachna International Institute of Research and Studies, Faridabad, India
}

\begin{abstract}
Exponentially growing data, big data, dark data and data trash are throwing excellent opportunities in the world. But associated costs and risks are also significant. "Big Garbage in, Big Garbage out" seems new phrase in computing. This paper is motivated by risk and cost stresses on non-IT firms. Literature review, from management perspective, reveals lack of world's attention towards immortality of data in the data stores of the world and rising risks \& costs. Progressive digitization calls for regular elimination of data trash and consequent avoidable costs. Existing concept of Time to Live (TTL) or hop limit is eliminating huge data in transit on the internet system in real time. Similar concepts and tools could be potential help in reduction of size of data inventory. Paper presents a rudimentary model for expansion of concept of TTL with the assistance of user defined shelf life of data.
\end{abstract}

Keywords: Big Data, Shelf Life of Data, TTL, TCO Of Data, Data Inventory. 
Cite this Article: Sarvesh Kumar Tripathi, Dr Avjeet Kaur, Dr Rk Pandey and Dr Meghna Chhabra Time To Modify Operating Software (Os), Databases (Db) and TCP/IP Protocols for Data Trash Elimination, Based on User Defined Shelf Life of Data. International Journal of Computer Engineering and Technology, 10(1), 2019, pp. 138-156

http://iaeme.com/Home/issue/IJCET?Volume=10\&Issue=1

\section{INTRODUCTION}

Today's world is drawing direction from information, extracted from digital data and "Big Data". Information technology is producing information through data with sizable monetary budgets. In the quest of such information, huge sizes of data are created and stored. Promise from Information Technology is sky high, but high costs are serious concerns for non-IT firms. This paper reviews the growth of data from IT management perspective of non-IT firms, as opposed to computer science / computer technology perspective. Paper is motivated by existing opportunities for eliminating avoidable costs through filtering and elimination of data - trash from stored data and data in transit. Behavioral change towards creation and storage of data supported by technology is articulated to have control on growth in total cost of ownership of all data in the world. Parallels are drawn from technique of data filtration, by the concept of Time to Live (TTL) / hop limit in TCP/IP protocols of internet. Rudimentary model is proposed for modifications in OS, DB and internet protocols (IP) for elimination of data trash. Paper invites attention of IETF, OS and database vendors for modifications to offer option to define shelf life of data in their products.

\section{DIGITAL DATA, IT'S GROWTH AND EARLY SIGNS OF ASSOCIATED PROBLEMS}

Data can be generated by man or machine and may be stored and transmitted in the form of electrical signals and recorded on magnetic, optical, or mechanical recording media. Underlying common factor is consumption of electricity, in creation, processing, storage, retrieval and transmission of digital data. One fifth of electricity generated in the world is expected to be consumed by 2025 for handling of digital data [36].

Digital data originate from computing devices, digital camera, various types of sensors, grow and multiply with growth in digitization under the existing paradigm of digitize all, store all, store forever". [37]. Exponential growth of data is raising concerns, worry, unease, the beginning symptoms of management problem [28]. Problem do exist and growing. Storage of exponentially growing data has trespassed into the domain of managerial problem, it is no more technology problem alone [5], [20].

Early signs of the problems associated with storage of large size data known as big data are visible in terms of resource consumption, loss of security and compromised privacy [32]. Problem gets complicated further with the fact that $78 \%$ of stored data is trash. Only $22 \%$ of the data produced has semantic value, of which only $5 \%$ of the data is actually leveraged for analysis by businesses. EMC 2 study estimates that by $2020,35 \%$ of the data produced will hold semantic value [8].

\section{ROLE OF MANAGEMENT DISCIPLINE IN HANDLING DATA}

All data, today, is managed by computer technologists / scientists. They are better in technology but not necessarily best in dealing with management challenges. Management challenges begin where technology gives up, at least for time being. Examples of terminal deceases, population density, problem of air and water pollution, over use of plastic, climate change, crisis of trash, business competition and big data are all suitable cases where adequate technology is eagerly 
awaited. Till that time management discipline is engaged in dealing with the problems. Political tools, like blame games are also used as cover up for even management inadequacies.

Adjustments in the human behavior, humanity are called for, where management gives up, exhausting options of management and deceptions through politics. Humanity calls for conservative and disciplined human behavior under crisis [22]. Being conservative is argued for happier life by Chamber \& Bonnie in their work Conservatives are happier than liberals but why? Personality, Political ideology and life satisfaction [13], [3].

Literature on digital data growth is flooded with the tools and techniques to exploit data for profits. Same time, literature is also concluding the limitations of existing technologies [ 41]. There is scarcity of research and research material on problem side of exponentially growing data.

\section{COST STRUCTURE OF INFORMATION TECHNOLOGY (IT) INFRASTRUCTURE}

Cost structure of IT infrastructure is function of data size held by an individual or firm. Cost rises with rises in data size. Exponential growth in data size also leads to exponential rise in total cost of ownership (TCO) for a firm. Rising costs are single most pressing reason for the firms, migrating from captive IT infrastructure to out sourced IT infrastructure, polarizing around on-cloud storage facility providers [6].

Firms / organizations today can be categorized into two broad categories, one, whose net revenue comes from IT products and services and second, whose net revenue comes from nonIT products and services. First categories can be termed as IT firm and other one, non-IT firm.

IT firms have successfully created monopolistic or oligopolistic market for their products and services. Cost is not primary concern for IT firms as they have capacity to pass on costs to non-IT firms through invasive marketing. Monopoly or oligopoly of these firms is maintained through their capacity to sell technology in development stage, fast changes in the versions of same technology and highly selective, controlled dissipation of know-how of their products. Such know-how by-passes the traditional schooling and university system. Traditional school and university education are of little use, if education is not supplemented through branded technology specific know-how (branded knowledge) to the end user of technology. This knowhow is propagating in parallel to the traditional education system but at high costs. Mushrooming technology specific training centers is common site everywhere.

Cost is concern for non- IT firms. They are struggling to secure budgets for IT infrastructure and acquisition of new technology offered by IT firms for making them rich, overnight. It is a technology rush and a mad rush.

Cost is also a concern for non- IT firms because they are not able to pass on IT costs to their customers due to wider competition in non-IT products and markets. This paper analyses cost structure of IT infrastructure of non-IT firms and individuals.

Very little is available in literature on the IT cost structure for a non-IT firm, an open area for research. Some inferences can be drawn from an IT budget template [35] and a blog by Alessandra Gyben [12]. Following cost structure is drawn from experience of authors.

Total cost of ownership of IT infrastructure ( TCO ) [33],[1] is function of data size (TB), held by a firm and all other costs are functions of TB, like cost of power (Cp), Cost of space (Cs), cost of hardware $(\mathrm{Ch})$, cost of direct \& indirect manpower $(\mathrm{Cm})$, cost of software licenses (Cl), cost of consulting $(\mathrm{Cc})$, Cost on training / education $(\mathrm{Ct})$, cost of exit from a technology (Cs), cost of acquisition of new technology $(\mathrm{Cq})$, cost of security / insurance $(\mathrm{Cz})$ and cost of connectivity / bandwidth $(\mathrm{Cb})$. 
Sarvesh Kumar Tripathi, Dr Avjeet Kaur, KR Dr RK Pandey and Dr Meghna Chhabra

$$
\begin{gathered}
\mathrm{TCO}=\mathrm{Cp}+\mathrm{Cm}+\mathrm{Ch}+\mathrm{Ci}+\mathrm{Cc}+\mathrm{Ct}+\mathrm{Cs}+\mathrm{Cq}+\mathrm{Cz}+\mathrm{Cb} . \\
\mathrm{Cp}, \mathrm{Cm}, \mathrm{Ch}, \mathrm{Ci}, \mathrm{Cc}, \mathrm{Ct}, \mathrm{Cs}, \mathrm{Cq}, \mathrm{Cz}, \mathrm{Cb}=\mathrm{f}(\mathrm{TB}) .
\end{gathered}
$$

It is experienced that cost components are dependent on single independent variable i.e. data size TB. If TB increases, all other costs also increase at varying rate. Only hardware cost $\mathrm{Ch}$ is seen decreasing but it is off-set by other costs quickly. If data growth is exponential, TCO would also grow at exponential rate and tend to reach infinite from the perspective of cost bearing capacity of firm, leading to viability concern of the firm. This is precise concern of authors with rising data size.

Exact cost information, spread across departments, is closely guarded secrets of the organizations, difficult to gather and compare. Comparison is further becoming complicated due to heterogeneity of technologies and purposes. IT Brand pulse has made an attempt to have comparison of TCO for $250 \mathrm{~TB}$ data for five years [2]. Estimates of TCO for data storage varies in the range of $\$ 600$ to $\$ 1400$ per TB for 5-year time period. TCO may rise to more than double, 2.41 times in 05 years as shown in figure- 01 .

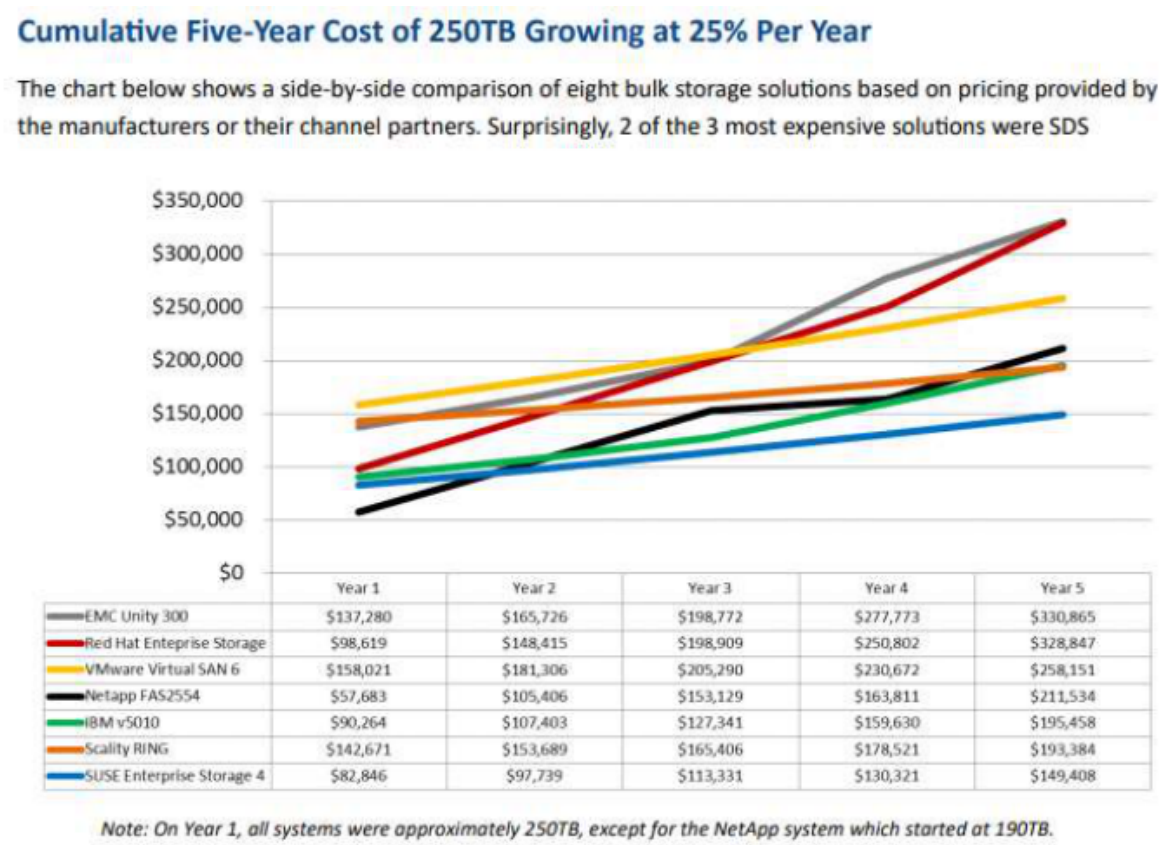

Figure 15 Year TCO Case Study by IT Brand Pulse

Source: Berry, 2016[2]

Grytz R and Grimberghe, AK have made very critical observations on IT infrastructure costs, costing of big data-based business intelligence and analytics (BI\&A) in the companies, in their work -Business Intelligence \& Analytics Cost Accounting: A Survey on the Perceptions of Stakeholders. They observed

Current discussions in the field of BI\&A are dominated by potential benefits of big data the costs of establishing and maintaining BI\&A systems are often overlooked. Due to complex architectures, in addition to the high speed of innovation in technology and methods, the costs of BI\&A have recently increased. The costs associated with such systems need to be transparent to management to allow for correct business decision-making. We believe, this lack of cost transparency is a significant driver for increasing BI\&A costs [11].

Fast rising costs is precise concern of authors with rising data size. For a non-IT firm data size above few TB's is a big data. 


\section{BIG DATA, BIG COSTS}

Term "Big Data" has come in circulation recently. Various attempts are evident in literature to define big data. A short survey paper by Jonathan Stuart Ward and Adam Barker presents most updated definition of big data as -

Big data is a term describing the storage and analysis of large and or complex data sets using a series of techniques including, but not limited to NoSQL, MapReduce and machine learning [31].

This definition too, appears ambiguous, reflects point of view of technology vendors and usage of data. Quantification of size and cost perspective of end user of big data have been ignored in attempts to define big data.

Footmarks of quantification of big data are found in the literature. One such quantitative definition of big data is referred by Intel as Intel is one of the few organizations to provide concrete figures in their literature. Intel links big data to organizations "generating a median of 300 terabytes (TB) of data weekly [17]. Cost definition of the big data can only be termed as "big cost" in currencies, individuals and firms dealing with it. Another open area for the research.

Captive data centers which were created in the propagation period of ERP could not sustain, due to high TCO, for managing data even sizes below $10 \mathrm{~TB}$, which were accumulated in the time frame of 05 years. Migration from captive data centers to on-cloud storage is widely evident, due to cost reasons alone. Total cost of Ownership (TCO) growth rate has been estimated at $25 \%$ per annum. Genuine concerns of cost are evident from figure -02 [33]. Growth in the profit margins in the most companies are much below the growth rate of TCO on captive storage of data.

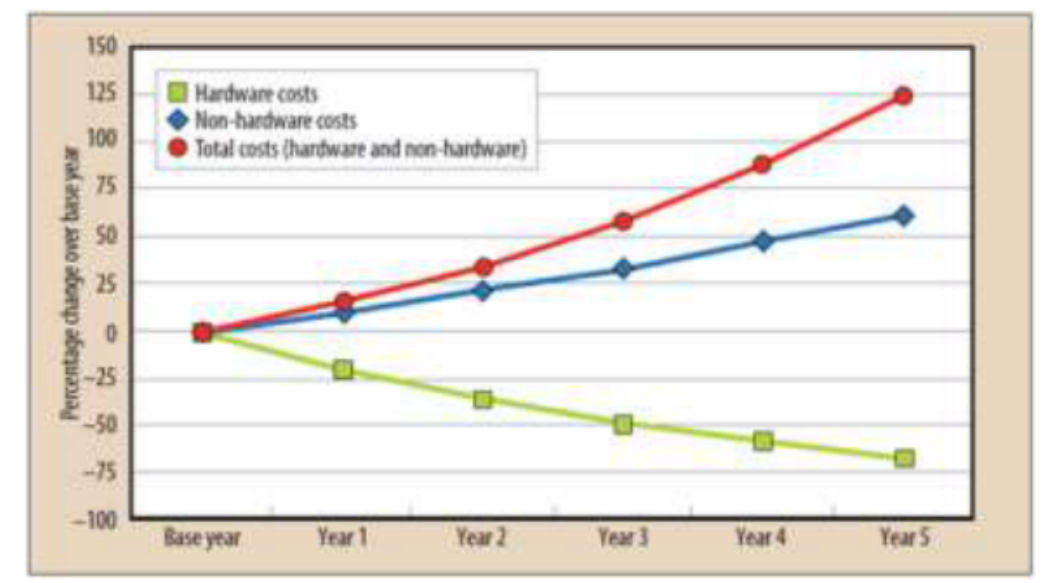

Figure 2 Growth Rate of TCO On IT Infrastructure

Source: Tallon, 2013[33]

A comparative study done by Forrester for data size of $100 \mathrm{~TB}$, provides cost reasons for the organizations to rush for on-cloud data storage [25]. On-cloud data storage is estimated to be one third cheaper than data storage in captive data centres. Data size of $100 \mathrm{~TB}$, it is still data and not the big data for data technology firms. 


\section{COMPOSITION OF BIG DATA}

Big data is composed of streaming data and stored data. Stored data is composed of online data, off-line data. Both type of data is structured or unstructured data. Most of off-line data is dark data.

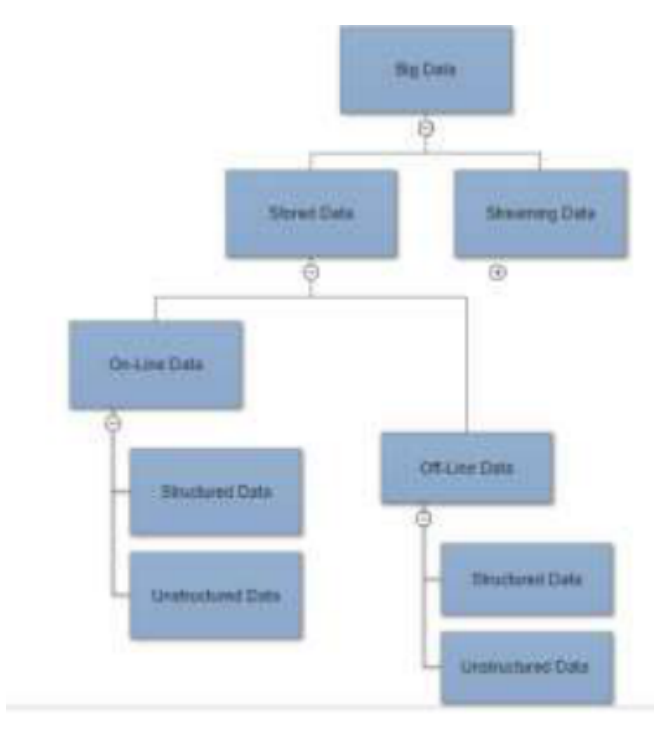

Figure 7 Composition of Big Data

Structured data largely comes from traditional database and unstructured data is collection of texts, photos, videos, blogs, books and manuals. Streaming data and online data stored either in RAM or ROM is directly accessible to the data mining and analytics tools. Data which is not online, constitutes very large size of data, recently being called "Dark Data".

\section{DARK DATA}

Dark data is data which is acquired through various computer network operations but not used in any manner to derive insights or for decision making [7].

Gartner define dark data as the information assets organizations collect, process and store during regular business activities, but generally fail to use for other purposes (for examples analytics, business relationships and direct monetization). Similar to dark matter in physics, dark data often comprises most organization's universe of information assets. Thus, organizations often retain dark data for compliance purpose only. Storing and securing data typically incurs more expenses and sometime greater risk than value [9]. Following sub categories constitute chunk of dark data.

1. Customer Information

2. Log Files

3. Employee Information

4. Survey Data

5. Financial Statements

6. Email Correspondences

7. Account Information

8. Notes or Presentations

9. Old Versions of Relevant Documents

10. Temporary notes on text files 
To Modify Operating Software (Os), Databases (Db) And Tcp/Ip Protocols for Data Trash Elimination, Based on User Defined Shelf Life of Data

\section{HOW MUCH OF DARK DATA}

It is sizable chunk of data. Broad estimation done by IBM suggest only $20 \%$ of big data is visible and rest $80 \%$ data is hidden from computer technology. This is translated into $35 \mathrm{ZB}$ (approx.) data to be dark data by year 2020. Graphical representation of relative sizes of Dark Data, Big data and traditional enterprise data is shown in figure - 04 and figure - 05 [23], [26].

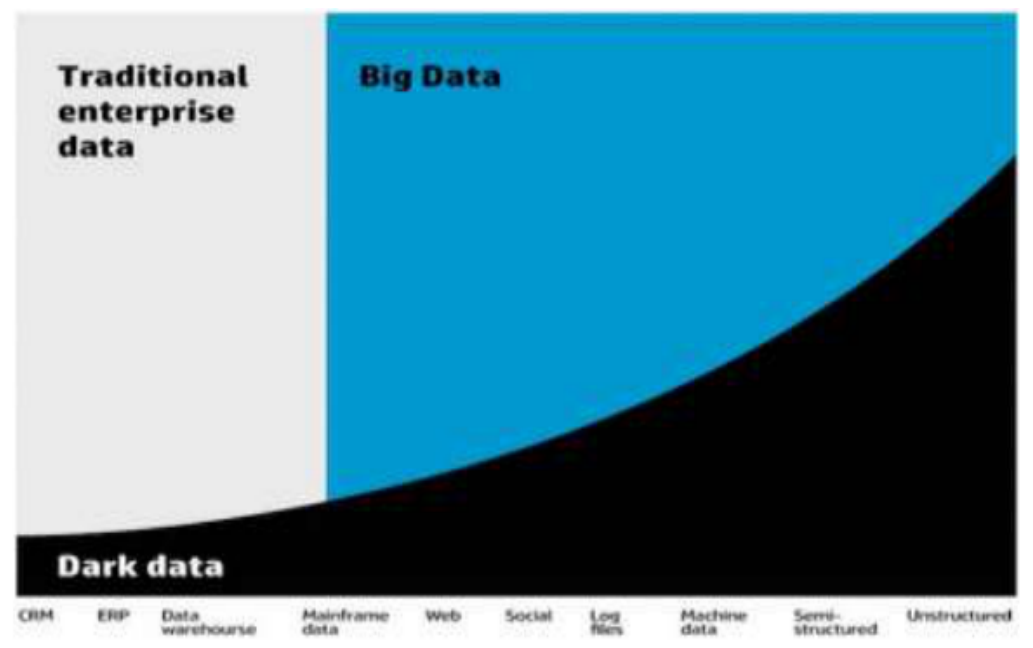

Figure 4 Composition of Big Data

Source: Progressive Tech.org.,2018[24]

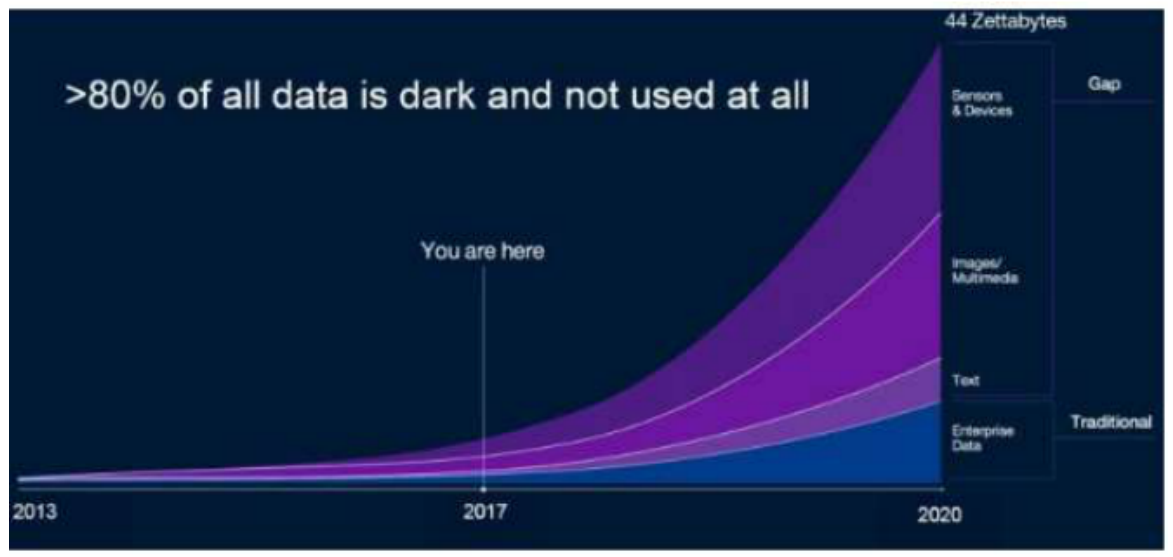

Figure 5 Data Waiting for Use

Source: Schroeer, 2017[26]

\section{BIG DATA, HOW BIG?}

There are various estimates on the size of big data. Gartner has estimated it to be 1.1 'brontobyte' (1027 bytes) of data in 2020 [26]. IDC predicts 44 ZB (1021 Bytes) data size by 2020 [16].

Author's personal data (mostly data on mobile phone) grows at the rate of $10 \mathrm{~GB}$ per month. Imagine the size of data generated by 5 billion (approx.) mobile users in the world [29].

IDC study suggests the growth rate of 7.0 ZB data per year. Data accumulation under current paradigm "Digitize all, store all, store forever" is expected to be mammoth. As technology is lagging behind for cost effective value generation from mammoth data sizes, 
management discipline needs to take early cognizance and confront existing paradigm of data accumulation.

\section{WHERE IS MY DATA IN THE CYBER SPACE? I HAVE RIGHT TO KNOW}

Every individual is a cyber entity today. It has cyber existence in the form of profile, personal data and official data under his / her ownership. Data pertaining to individuals is collected by schools, hospitals, banks, electricity company, multiple Government agencies, social media company, email service provider and other service providers.

All these data collection done by multiple agencies, gradually moving to on- cloud data storage companies, as in -house data storage is becoming costly. There are chances that my data may be stored with any or all of following companies, currently dominating on- cloud data storage market.
1. Amazon.
2. Google.
3. IBM.
4. Teradata.
5. Oracle.
6. SAP.
7. HP Enterprise.

Lot of data is lying in the digital scrap yard like in figure -06

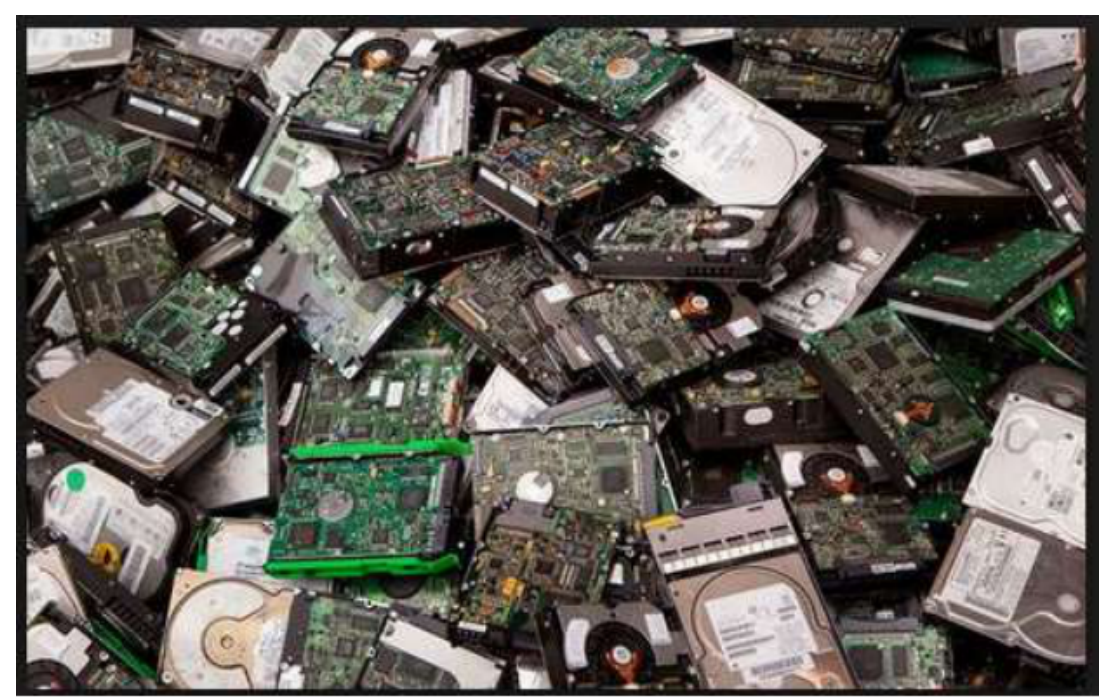

Figure 6 Data in hardware scrap

An individual does not have any means to know. Where his cyber personality actually exists on the earth? How many hands it has changed? How many copies are maintained? Who else, other than authorized person is using? How long such cyber personality will exist on the earth? All above questions are relevant for an organization also. Situation calls for providing technology and tools in the hands of individual to have control on his / her data floating in the cyber space. One is not sure, he can decide, not to exist in cyber space or he can recall his / her data from cyber space. At the most he can wish to exist in cyber space based on shelf life of data defined by him, a concept needs to evolve. 


\section{USAGE OF BIG DATA}

Primary usage of big data is centered around finding value through three activities, identifying pattern(s), analysis of pattern and predictive likelihood of an event [10].

Most of structured data is retained for statutory compliance and expected demand of data to support legal claim. Philosophy practiced in the organization about retention time of the data is to "Let us keep, someone may need it". Most popular usage of big data today are -

\section{DATA MINING AND ARTIFICIAL INTELLIGENCE}

Data today is seen new gold or new oil for the IT companies like Google, Facebook and Microsoft to prepare computers to identify objects and photos and analyze consumer behavior using artificial intelligence technology.

With help of companies like Datalogix, Acxiom, BlueKai, and Epsilon. Facebook uses your data to target Ads. These companies collect information about you through your mailing list, browser cookies/cache and also through various other means of data pooling. Later they sell these data to Facebook and other social networking sites. It is from there, ads start appearing on the websites you visit, based on the products you had previously visited on your favorite shopping site. The data collected from various sources can be used to develop new innovative products and services.

Amazon is using the highest end analytics the predictive analytics. They have recently filed for a patent on an analytic model that can predict what you're going to buy before you buy it. Predictive analytics tells them, there is chance that you are going to purchase a product in the coming day or two. They are so confident in the accuracy of their algorithm that they will ship you that product before you buy it. Let's say something from Amazon shows up on your doorstep that you didn't order, but it's something that you wanted. So, you pay for it. This is not yet a production feature of Amazon.com but expected soon.

\section{MACHINE LEARNING}

Process of learning by machine, generally computing machine through application of artificial intelligence (AI) drawn from big data. It provides systems the ability to automatically learn and improve from experience without being explicitly programmed. Machine learning focuses on the development of computer programs that can access data and use it learn for themselves.

Data mining and machine learning usage are dependent of the artificial intelligence (AI). Data mining looks for predicting an event based on the data, while in machine learning, performance of machine is improved by experience gained through data / big data.

\section{DATA MONETIZATION}

Monetization of data is happening through economic activities in storing, analyzing and selling data. Though new, monetization through legal exchange (sale) of data is developing into big commerce at the massive scale without geographical boundaries. Full-fledged data exchange is operational in China [20]. Success stories from Amazon, Cargill, Merck [4] are leading others to take plunge into big data for profits.

Direct benefits from big data are realized from industry-specific results such as fewer medical errors, lower expenses, shorter hospital stays in the healthcare sector, improved pricing decisions in the energy trading sector, enhanced customer satisfaction in the automotive sector, and real-time decision-making concerning scheduling, market analysis, and ticket pricing in the airline industry [33]. 
Extremes of opportunities are presented by Fan Liang et al. in their work "A Survey on Big Data Market: Pricing, Trading and Protection". Data trading of used data is being argued to generate value through inter changeable technologies of data mining and analytics [20].

Liang's et al work highlights keen involvement of management discipline, the marketing management principles in determining the price, data placed for trading. Such involvement of management discipline in management of stocks of data has been emphasized by authors in their work "Taming Tsunami of data by principle of inventory management.

What is connect between above two works? Work on pricing of tradable data has focus on opportunity side of the big data while author's work puts focus on inventory of tradable data. Efficient inventory management of big data can complement enterprise of data trading, cost reduction, quality and security improvements.

Study by Markets and Markets, projects data monetization market size to grow from USD 1.42 Billion in 2018 to USD 3.12 Billion by 2023, at a Compound Annual Growth Rate (CAGR) of $17.1 \%$ during the forecast period [21].

Usage of big data can be summarized into generation of fundamental value, realignment of value chain and loss avoidance. Snooping and invading are frightening aspects of big data.

\section{DATA TRASH}

Popular phrase "Garbage in, garbage out" still prevails in computing world. Now it is to be rephrased as "Big Garbage in, Big Garbage out". Data size is growing and so is the case with data garbage / trash.

Technology firms are focused upon tools and technology for mining the gold from data, quality of data is taking back seat. Concept of data trash is ambiguous, it depends upon the user of data. Hicks has noted in his work that -Waste within the context of information management is less clear and not generally as visible [14].

For the context of this paper, information waste or data trash is considered, that data, whose storage cost is unnecessarily born by the user paying for the storage, transmission and retrieval of data.

Focal point of the technology firms and technology research is on the data usage stage of data life cycle. Consequently, new promises keep coming to convert data into gold or mine gold from data. Hadoop ecosystem, MapReduce, IBM's Watson, Data Lakes, NoSQL databases, are few examples of the technologies leading world to be data centric.

In the quest of reaping profits from big data analytics and economy of scale in storing data on cloud creating hype of benefit to all. In reality major success stories are reported from technology firms or very large organization capable of storing large volumes of data for themselves. Such benefits to the success stories are contributed by inadvertent exposures of personal data on internet, on social media or to the sales organizations.

Apart from advent of new technologies every day, success stories from big data are leading world to create more and more data, somehow store them and ignore archiving and purging stages of the life cycle of data. As big data analytics works better on live / on-line data, there is general reluctance in archiving / purging. Trends are rather bringing archived / off-line data to life for data mining and analytics.

Experience of past 25 years of digital era shows us the manners in which data are purged. Data purging happens mostly unplanned and painful. It is done largely at the stage of change in technology, change in ownership or natural calamity. Data is still lying in floppy discs, magnetic tapes, compact discs, flash drives mediums. Automatic purging of data takes place with the shelf life of data holding media. As more and more new data is created and dark data 
becoming brighter, total stock of data in the world is expected to evolve into a data monster with monster costs.

Evolution of tools and technologies are far lagging in capabilities to deal with this monster. Statement by Courtney Kay of brand publis summarizes the current state of technology and data, the idea of what cognition represents creates a potential life raft in a world where we're drowning in technology and data [19].

Purging stage of the data life cycle is not attracting due attention of the researchers. As a consequence, size of digital data is rising and rising very fast. Authors apprehend a crisis in making like crisis of municipal wastes in the world. Crisis of municipal waste is known as "Trash Crisis" [27].

\section{DATA CRISIS A NEW TRASH CRISIS}

Though, Big data is seen opportunity today, but a crisis is in making. As technology has already given up, at least for time being. Present state of technology to deal with big data for mining, the terminal use of all accumulation of digital data has been concluded by $\mathrm{Wu}$ Xingdong et al. as -

Traditional data models are incapable of handling complex data in the context of Big Data. Currently, there is no acknowledged effective and efficient data model to handle Big Data" [41].

Impending data crisis, like trash crisis [27] is already being recognized. World is waiting for technological breakthrough to deal with big data. Management discipline is active through existing management tools of economy of scale, transport problem, capacity planning, location decision and linear programming to minimize cost and maximize benefit to the individual or to the firm. Cloud computing and data lakes are more of management solution to the problem than technological solutions.

Consequential impacts on the environment are being ignored. Adverse environmental impacts are inevitable as huge units of electricity, single most prominent resource, is consumed in handling big data.

Trash (garbage) is health hazard due to potential contamination, breeding ground for bacteria and virus. Data trash too, is hazard as potential raw material for unwanted information exchange, denial of services (DoS) and computer viruses. At the extreme, unhygienic, unsecure storage of data could be threated to lives too, if falls in the hands of criminals or enemy country.

Problem of trash (solid and liquid wastes) is analogous to the problem of big data. Swelling garbage mountains, fast filling of land fill sites, ever growing rate of trash generation, more trash in more developed country, environmental concerns, limitations of existing technology, focus on efficient management are common features of the problems of trash crisis and big data, making them analogous in nature.

In real world, tangible and intangible objects or information make quick encroachments from one functional discipline to the other. There are opportunities for exploration and learning from interrelated, analogous disciplines / domains. Multi discipline research would help keeping interrelated disciplines complimentary to each other in terms of feeding problems and solutions to each other. This paper is therefore attempting early warning for computing disciplines by drawing parallel from the trash management. It has become inevitable to focus on the purging stage of data life cycle. 


\section{SIZE OF SOLID WASTE GENERATION}

Current global municipal solid waste (MSW) generation levels are 1.3 billion tons per year (approx.), in 2010 and are expected to increase to approximately 2.20 billion tons per year by 2025. This represents a significant increase in per capita waste generation rates, from 1.20 to $1.42 \mathrm{~kg}$ per person per day in the next fifteen years [40].

\section{SIZES OF DATA GENERATION}

Digital data size on the earth is growing from $20 \mathrm{ZB}$ in 2016 to $163 \mathrm{ZB}$ in 2025 [16]. Concept of per capita consumption of data would be interesting innovation in the computing fraternity.

Crisis of trash and impending data crisis are characterized by its huge sizes and huge growth rates. Only difference in both the problems is age of the problem, problem of trash crisis is older than to be problem of big data. This age difference gives opportunity to learn from the similar problem and initiate early emphasis on the humanity side of the solution to the impending problem. Los Angeles Times asked question in April' 2016, The world's trash crisis, and why many Americans are oblivious [27]. Similar question can safely be asked about impending tsunami of data, why people are oblivious?

\section{INNOVATIVE MANAGEMENT OF TRASH}

One can always see few people at landfill site or at mountain of garbage busy mining things valuable to them. This activity is like data mining up to certain extent. Garbage mining does promise some benefits to miners, but such benefits do not justify huge environmental costs accumulating through ever growing trash dumps.

Some business opportunities are also proposed for converting value from trash. Garbage trades are reported in some part of earth. Such opportunities are detailed in a book Garbology: Our Dirty Love Affair with Trash by Edward Humes [ 15].

Similar trade opportunities are reported in big data domain too. Such trades have been objected due to security and privacy concerns. Though, there are business opportunities in trading trash or big data, but such enterprise is expected to be in the grey domain of human endeavor. Quality and flavor of life in the trade of flowers is defiantly superior to the life in the trade of trash.

\section{RISKS WITH POOLED AND POLARIZED STORAGE}

There are apprehensions about perennial availability of data from rising centralized stores, monopolistic or oligopolistic data storage market. These apprehensions are about -

How much resources? mainly electricity, needed to store all the digital data, size increasing exponentially.

What if free trades between countries is interrupted? What if data storage facility got destroyed? What if data is stolen? What if technology to access old data become extinct?

Above apprehension are not imaginary. Library in Brazil caught fire and data got lost forever [34]. Moreover, not to forget Murphy's law. If something can go wrong, it will. Time is only factor [39]. Apart from tremendous opportunities with huge data in the data store of the world, apprehension about privacy, security, TCO, denial of service (Dos) and misinterpretation of facts, are real. 


\section{MITIGATION OF RISK BY SIZE REDUCTION}

Risks with big data can be better addressed if size of data or growth rate of stored data is reduced. Reduction of data growth rate through trash elimination can improve quality of data thereby reduced cost of ownership (TCO) and improved interpretation. Literature is rich in contents on the tools and techniques for usage of big data, but very little is available on data waste minimization and trash avoidance.

Trash with respect to digital data is debatable [14]. Technology companies do not see any thing as trash till mining stage of data handling. Trash is recognized at the data preparation and cleaning stages of mining. Data trash is recognized with respect to the objective of data analysis and recognition of trash is done by domain experts or domain end users, these are same people who create the data and hand over it to data storage managers.

Focus of this paper is to review tools and techniques used for data trash minimization and trash avoidance. Paper is also exploring possibility usage of such techniques at larger scale.

\section{EXISTING TECHNIQUES FOR DATA TRASH CONTROL AND TRASH AVOIDANCE}

Authors came across two techniques already in use for data load and data trash avoidance in the computing system. First, Time to live (TTL) or hop limit for data packages and TTL for file reputation score.

\section{TIME TO LIVE (TTL) OR HOP LIMIT}

Concept of time -to-live like shelf life is being used since advent of internet. Data packets, fragmented pieces of digital content are transmitted on internet. Traffic of such transmission of the data packets is regulated through strict transmission rules, called internet protocol (IP). Internet protocols are maintained and enforced by Internet Engineering Task Force (IETF) [18]. Internet protocol adds control information to the data packet as in figure - 07.

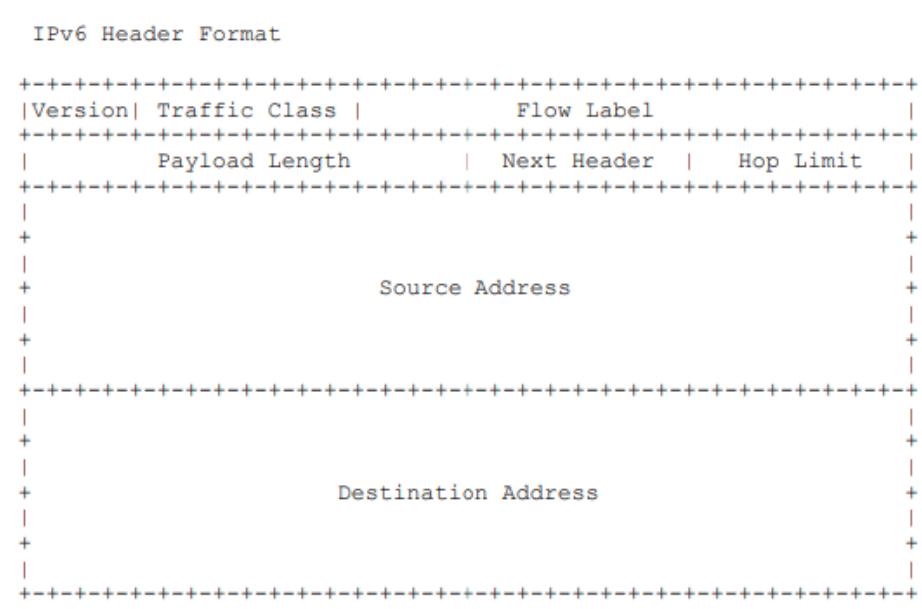

Figure 8 Hop Limit or time to live (TTL)

Source: IETF, 2017[18]

Concept of hop limit or TTL controls the life span of the data packet on the internet. Sender machine (computer or switch) assigns an integer value in hop limit field. This integer value is decremented by 01 with each hop on the receiving machine. Data packet received with hop limit of 0 is discarded by receiving machine or internet node. If not discarded, such data packets 
would remain in internet, increasing the data traffic congestion, slow down traffic or choke the traffic at some point.

In the context of digital data, data packets which are discarded by internet system are data trash. Such trash is massive considering the overall data travelling on the net, 121694 Petabyte per month in 2017 [29]. Same amount of data trash is eliminated from the system in a month time by use of TTL technique.

Amount or time for which such trash will remain in system is controlled by operating software. Different software assigns different hop limits or TTL to the data packets for example Unix assigns TTL of 64, windows 128 and Solaris assigns TTL of 254. Point here is, we have a system in place which recognizes and eliminates the data trash from internet network system.

\section{TTL FOR FILE REPUTATION SCORE}

File reputation scoring technique is a new technique for assigning a score to a digital file based on its reputation. Usage are traced since $2014-15$. Technology is patented by Symantec Corporation, Mountain View, CA, US under title Individualized time-to-live for reputation scores of computer files [38].

Technology is being used to prevent computer virus, malware attack on computers. An individual file is assigned with a reputation score based on its origin, type, history like attributes. This score is then assigned a time to live (TTL) or shelf life to the score. Based on the reputation score, file can be downloaded on the requesting client or discarded. Reputation score once assigned is not retained by file but discarded after predefined shelf life or time to live.

Technology is reported to be used by almost all anti-virus vendors like Mcfee, symantec and trend micro. Exact working of reputation score is kept as trade secret by antivirus vendors. Validity period or shelf life of software licence are already in use.

Above technologies have evolved primarily for keeping data load on the computing system under control and avoiding choking of systems through genuine or mala fide intent of the data overload. These technologies are successful in keeping check on data traffic and transmission nodes, without any impact on the swelling data stores.

Similar technology needs to evolve which can aid in control on trash recognition, trash elimination and controlling exponential growth of digital data in data stores. Authors foresee user defined shelf life to each file as potential technique for digital trash elimination.

\section{SHELF LIFE OF DIGITAL FILE ASSIGNED AT SOURCE}

Shelf life is defined the length of time that a commodity may be stored without becoming unfit for use, consumption, or sale. The concept of shelf life applies to all goods that deteriorate overtime due various reasons, although a common man encounters the term most frequently when he purchases what is known as FMCG - fast moving consumer goods.

A digital content is practically indestructible, if the media it is stored on is undamaged. As such, it can be said that a digital content is 'immortal'. While this has advantages, all digital content takes up space that leads to different problems.

All digital content however is not equally important / relevant, and such importance/relevance / value may change with passage of time. Many digital documents have a date/time till which they are important/relevant after which they lose their importance and value. Storing such documents thereafter is not required and can only add to problems and costs. It can be said that there is a practical 'shelf life' for digital content such as these after which its storage is no longer required since it can no longer be 'consumed'.

At the same time, storage devices also have an expiry life time before they fail. In case a storage device with important documents stored on it fails, the documents can be irretrievably 
lost with disastrous results. Recovering from loss of such documents can take tremendous efforts, time and money. In many cases, full recovery may never happen.

Predefined shelf life of software codes or embedded microprocessors would help in future to contain accidents due to electronically controlled machines and weapons. Once put in use, concept of shelf life would prompt vendors of software and hardware to develop and maintain the shelf life of each distinct piece of digital data in its metadata.

Though hypothetical today, in future there will be needing to program a robot with mechanism of its self-destruction beyond certain useful life for saving the accidental damage to humans. Concept of shelf life would be vital for such mechanism. Data security will be taken care in better way if there is option to classify various data based on its shelf life.

\section{RUDIMENTARY MODEL FOR TRASH ELIMINATION THROUGH USER DEFINED SHELF LIFE}

1. Operating software (OS) provides option to declares shelf life of file at the time of saving the file first time, same as "Save as" options in windows. This option is provided for each kind of user data file excluding system files.

2. This shelf life becomes part of metadata of file.

3. OS provides a back-ground process for automatic deletion of expired files.

4. Database provides option to declare shelf life to each database record at the time of committing the record, like creation time stamp.

5. Storage media is sold with its shelf life. OS checks the shelf life of media and provides recommendation for storing content, compatible to the shelf life of data.

6. Applications are developed to generate report on expiring content of data and approaching expiry date of storage media.

7. End user gets option to reassign shelf life for the file created by him / her.

8. TCP/IP inherits shelf life from the meta data of the content (message) file. Data packets containing expired message / data are automatically assigned TTL value zero and discarded /purged from the system.

9. Internet sends back message to sender as "Message could not be delivered, due to expired content".

10. Duplicate files should inherit same shelf life.

Implementation of above model (Figure- 08) would eliminate trash from data storage system and thereby retarding the data growth, improve data quality, reduced resource consumption and improved analytics. Non- IT firms will be in better position to store their data in captive storages. 


\section{USER DEFINED SHELF LIFE BASED DATA TRASH ELIMINATION}

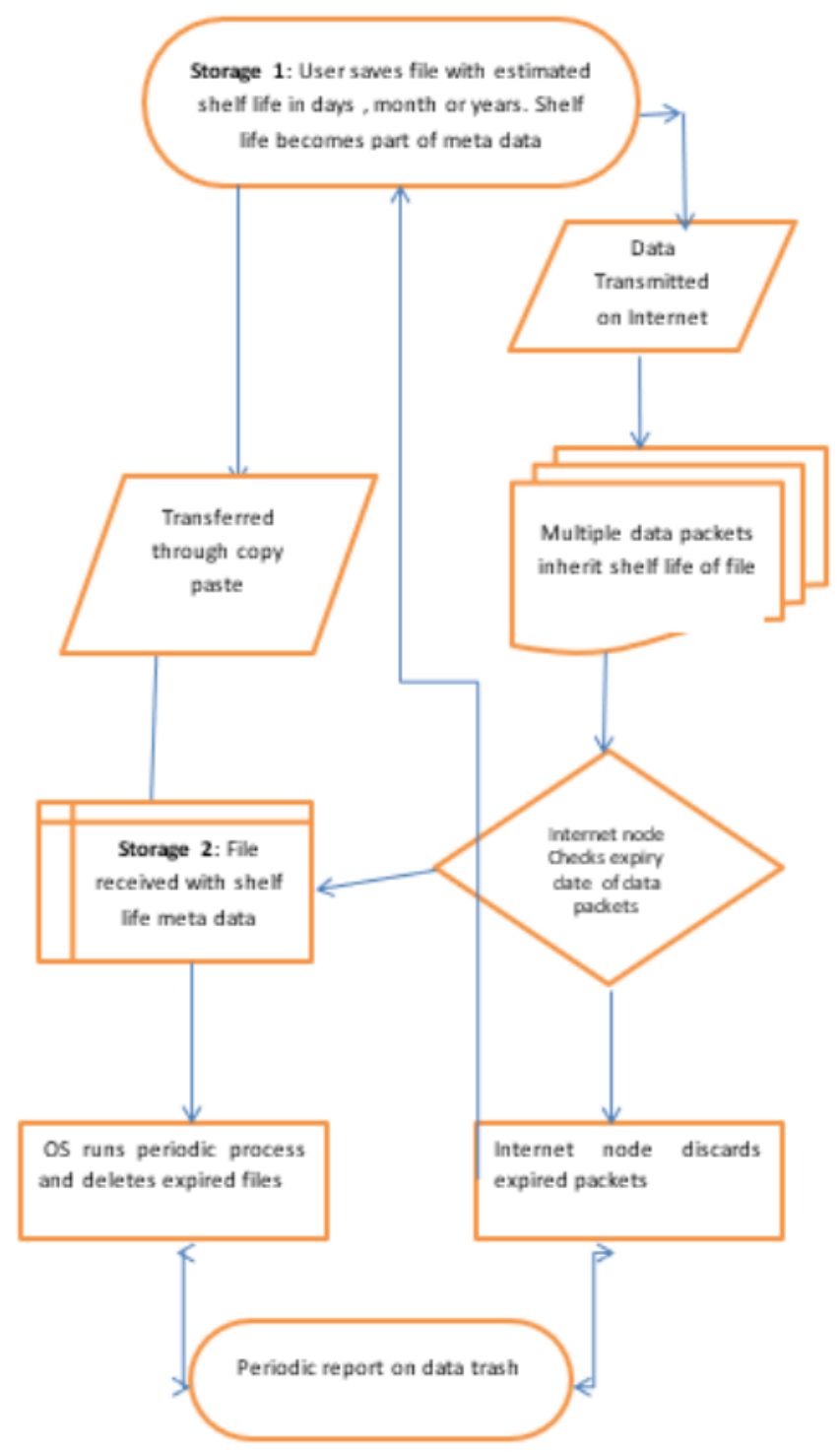

Figure 8 Flow chart for user defined shelf life-based data trash elimination

\section{CONCLUSION}

Non- IT firms and individuals are struggling to cope with costs related to exponential growth of data, coupled with storage of large amount of data trash. User creating data, does not have any control on data purging / deletion. Credible concept, policy and technology in the hands of data creator can help in overcoming impending problems with tsunami of data. Existing computer techniques of time-to-live (TTL) have potential to overcome the challenges up to large extent by on-line data trash recognition and elimination, if expanded. Similar concept is observed potential tool for data trash elimination and trash avoidance. Large organizations engaged in IT products and regulator of internet need to take notice of the opportunity and modify / design their products for maintaining user defined shelf life of data files. With such provision, trash free refined data would help resource efficient inventory of data in the hands of individuals / firms and world as whole. 
To Modify Operating Software (Os), Databases (Db) And Tcp/Ip Protocols for Data Trash Elimination, Based on User Defined Shelf Life of Data

\section{REFERENCES}

[1] Avamar Technologies, Inc. (2005). Total Cost of Ownership Analysis. Retrieved from http://www.mosaictec.com/pdf-docs/avamar/avamar_tco.pdf/.

[2] Berry F. (2016, December). 5 Year TCO Case Study. Retrieved from https://itbrandpulse.com/wp-content/uploads/2016/12/TCO2016012-Enterprise-StorageTCO-Case-Study-v1.pdf/.

[3] Chambers J.R., Bonnie M.L. Conservatives are happier than liberals but why? Personality, Political ideology and life satisfaction. Journal of Research in Personality 46(2). pp.127146. (2011, December 09).

[4] CIO. (2018). 10 data analytics success stories: An inside look. Retrieved from https://www.cio.com/article/3221621/analytics/6-data-analytics-success-stories-an-insidelook.html/.

[5] Clark J. (2014, April 14). Bored with trading oil and gold? Why not flog some CLOUD servers? The Register. Retrieved from https://www.theregister.co.uk/2014/04/14/sick_of_trading_pigs_oil_and_wheat_how_abo ut_cloud/.

[6] Cook J. (2018). What are the Benefits of Migrating to the Cloud? Retrieved from https://cloudacademy.com/blog/cloud-migration-benefits-risks/.

[7] Datumize.com. (2018). The Evolution of Dark Data and how you can harness it to make your business Smarter. Retrieved from https://blog.datumize.com/evolution-dark-data/.

[8] Dezyre.com. (2015 August 26). Big data timeline- series of big data evolution. Retrieved from https://www.dezyre.com/article/big-data-timeline-series-of-big-data-evolution/160.

[9] Gartner.com. (2018). What is dark data. Retrieved from https://www.gartner.com/itglossary/dark-data/.

[10] George G., Haas M.R., Pentland A. Big Data management. The Academy of Management Journal 57(2),321-326. (2014, April).

[11] Grytz R., Grimberghe A. K. Business Intelligence and Analytics Cost Accounting: An Empirical Study of the Perceptions of Stakeholders and Their Implications. International Journal of Systems and Service-Oriented Engineering (IJSSOE) 8(3). doi: 10.4018/IJSSOE.2018070103. (2018).

[12] Gyben A. TCO structure. Retrieved from https://technologyadvice.com/blog/sales/totalcost-ownership-crm-marketing-automation/. (2018, May 30).

[13] Hamrick K.S. (2017, July). Want to live a happier life? Be a conservative! Retrieved from https://www.foxnews.com/opinion/want-to-live-a-happier-life-be-a-conservative.

[14] Hicks B. J. (2006, Dec 01). Lean information management: Understanding and eliminating waste. International Journal of Information Management, 27(4), 233-249.

[15] Humes E. Garbology: Our Dirty Love Affair with Trash. New York. Penguin. (2013).

[16] IDC. Data age 2025: the evolution of data to life-critical. Retrieved from https://www.seagate.com/files/www-content/ourstory/trends/files/Seagate-WPDataAge2025-March-2017.pdf/. (2017).

[17] Intel IT Centre. Intel Peer Research on Big Data Analytics. Retrieved from https://www.intel.com/content/dam/www/public/us/en/documents/reports/data-insightspeer-research-report.pdf. (2012, August).

[18] Internet Engineering Task Force (IETF). Internet Protocol, Version 6 (IPv6) Specification. Retrieved from http://www.rfc-editor.org/rfc/pdfrfc/rfc8200.txt.pdf/. (2017, July).

[19] Kay C. (2016, Sept 26). Cognition and the future of marketing. Retrieved from https://www.ibmbigdatahub.com/blog/cognition-and-future-marketing/. 
[20] Liang F., Yu W., An D., Yang Q., Fu X. and Zhao W. A Survey on Big Data Market: Pricing, Trading and Protection. IEEE Access, vol. 6, pp. 15132-15154. DOI: 10.1109/ACCESS.2018.2806881. (2018, February 16).

[21] MarketsandMarkets.com. (2018). Data monetization market size. Retrieved from https://www.marketsandmarkets.com/PressReleases/data-monetization.asp/.

[22] Navon D. The importance of being conservative: Some reflections on human Bayesian behaviour. British Journal of Mathematical and Statistical Psychology 31(1), pp.33-48. (1978, May).

[23] Pal K. (2015, November). What is the importance of Dark Data in Big Data world? Retrieved from https://www.kdnuggets.com/2015/11/importance-dark-data-big-dataworld.html/.

[24] Progressive Tech.org. (2018). Cost structure of IT department. Retrieved fromhttps://network.progressivetech.org/system/files/Sample\%20Tech\%20Budget.pdf.

[25] Reichman A. (2011, August 11). File Storage Costs Less in The Cloud Than In-House. Retrieved from https://media.amazonwebservices.com/Forrester_File_Storage_Costs_Less_In_The_Clou d.pdf.

[26] Schroeer T. (2017, May 09). Cognitive computing: Hello Watson on the shop floor. Retrieved from https://www.ibm.com/blogs/internet-of-things/iot-cognitive-computingwatson/.

[27] Simmons A.M. (2016, April 22). The world's trash crisis, and why many Americans are oblivious. Retrieved from http://www.latimes.com/world/global-development/la-fg-globaltrash-20160422-20160421-snap-htmlstory.html/.

[28] Smith G.F. (1989, August 08). Defining Managerial Problems: A Framework for Prescriptive Theorizing. Management Science Vol. 35(8), pp. 903-1028.

[29] Statista.com (2018). Global IP data traffic from 2016 to 2021 (in petabytes per month). Retrieved from https://www.statista.com/statistics/499431/global-ip-data-traffic-forecast/.

[30] Statista.com. (2018). Number of mobile users. Retrieved from https://www.statista.com/statistics/274774/forecast-of-mobile-phone-users-worldwide/.

[31] Stuart J., Backer A. (2013, Sept 20). Undefined by Data: A Survey of Big Data Definitions. Retrieved from https://arxiv.org/pdf/1309.5821.pdf.

[32] Sullivan F. O. (2018 May 07). Top Ten Major Risks Associated with Cloud Storage. Retrieved from https://www.cloudwards.net/top-ten-major-risks-associated-with-cloudstorage/.

[33] Tallon P.P. Governance of Big Data: Perspectives on Value, Risk, and Cost. Computer, 46(6), 32-38. (2013, June).

[34] Tarlach G. (2018, Sept 04). Dark Data: The Vulnerable Treasures Sitting on Museum Shelves. Retrieved from http://blogs.discovermagazine.com/deadthings/2018/09/04/darkdata/\#.W88TLHszbIU/.

[35] Techopedia.com. (2018). Definition of TCO. Retrieved from https://www.techopedia.com/definition/159/total-cost-of-ownership-tco.

[36] The Guardian (2017, December 11). Tsunami of data' could consume one fifth of global electricity by 2025. The Guardian. Retrieved from https://www.theguardian.com/environment/2017/dec/11/tsunami-of-data-could-consumefifth-global-electricity-by-2025.

[37] Tripathi S.K., Chhabra M., Pandey R.K. Taming Tsunami of data by principles of inventory management. Journal of Business and Management (IOSR-JBM), Volume (20), pp. 1-12. doi: 10.9790/487X-2006060112. (2018).

[38] Vijay S, RamZan et al. (2014, August 05). Time to live for file reputation scores. Retrieved from https://patents.google.com/patent/US8800030B2/en/. 
To Modify Operating Software (Os), Databases (Db) And Tcp/Ip Protocols for Data Trash Elimination, Based on User Defined Shelf Life of Data

[39] Wikipedia (2018). Murphy's law. Retrieved from https://ieeexplore.ieee.org/abstract/document/6547630/.

[40] World Bank. (2016). Waste generation. Retrieved from https://siteresources.worldbank.org/INTURBANDEVELOPMENT/Resources/3363871334852610766/Chap3.pdf/.

[41] Wu X., Zhu X. et al. Data Mining with big data, IEEE Transactions on Knowledge and Data Engineering. Volume: 26 (1). pp 97-107. (2014, January 01). 